\title{
Perancangan Sistem Proxy Server Menggunakan Protokol WCCPv2 dengan Konfigurasi Multi Router
}

Fatah Mumtaz A1 'Ala ${ }^{1)}$, Rinta Kridalukmana ${ }^{2}$, Eko Didik Widianto ${ }^{2)}$

Program Studi Sistem Komputer, Fakultas Teknik, Universitas Diponegoro

Jalan Prof. Sudharto, Tembalang, Semarang, Indonesia

Numbers of internet users are increasing incredibly fast. Ideally, this increasing numbers of users are also supported by capacity uplift, in this case an increase in bandwidth to maintain the standard services that received by the users. However, increasing the bandwidth not always becomes the first option since it is quite expensive. Implementing proxy server as content/cache engine is the other option available. It will cache the content that user requested and keep it for a while for servicing the other users that will request the same content in the future.

WCCP protocol is used to redirect user's traffic to the proxy server. The standard proxy server configurations are using single router with one or more proxy servers. This thesis is aims to design and implement proxy server system with multi routers configuration. Multi routers configuration is used as a failover mechanism to provide network high availability. It will use HSRP protocol to provide the high availability services.

Tests that conducted after implementation shows the increase in transaction and successful transaction by $296 \%$ and $284 \%$ also a decrease in response time as well as failed transaction by $18 \%$ and $99 \%$ consecutively. Failover test shows the percentage of packet loss amounted to $31,3 \%$ and 26,3\% for clients in VLAN 10 and VLAN 20 consecutively. The average time required for clients to reconnect to the internet after router failure is 7 seconds for clients in VLAN 10 and 6 seconds for client in VLAN 20.

Keywords : internet, proxy server, WCCP, HSRP, failover

\section{PENDAHULUAN}

$\mathrm{P}$ erkembangan teknologi jaringan komputer yang sangat cepat saat ini mengakibatkan terjadinya peningkatan pengguna teknologi tersebut secara signifikan. Hingga kebutuhan untuk mengakses jaringan komputer global (Internet) sudah menjadi layaknya kebutuhan sehari - hari untuk berbagai macam tujuan. Baik sekadar melihat feed media sosial, video streaming, maupun hanya untuk menjelajah internet. Fenomena peningkatan jumlah pengguna ini harus disiasati dengan penggunaan berbagai macam teknologi yang tersedia untuk tetap mempertahankan tingkat kualitas layanan internet yang diterima oleh pelanggan. Salah satu solusinya adalah menambahkan jumlah bandwidth yang dimiliki, dan penggunaan content/cache engine. Opsi penambahan bandwidth tidak menjadi prioritas utama karena memang cukup mahal dan harus dibayarkan secara berkala karena menggunakan sistem sewa. Penggunaan content/cache engine jauh lebih murah dan efisien dalam meningkatkan kualitas layanan, Blue Coat System menyediakan Blue Coat CacheFlow untuk jenis solusi yang berbayar, di sisi lain terdapat Squid/LUSCA yang merupakan solusi berbasis open source. Meskipun berbasis open source, Squid/LUSCA dapat diandalkan sebagai salah satu solusi.

Konsep penggunaan content/cache engine diterapkan dengan menempatkan content/cache engine sebagai proxy server antara jaringan lokal dengan internet. Content/cache engine akan menyimpan konten-konten dari internet yang pernah diakses oleh pengguna, ketika ada pengguna lain yang meminta konten yang sama, maka permintaan tersebut akan dipenuhi secara lokal oleh content/cache engine. Oleh karena itu, hal tersebut dapat mengurangi transmission costs dan download time. Pada sisi pengguna, mereka tidak menyadari bahwa sebagian besar permintaan mereka akan dipenuhi secara lokal oleh content/cache engine, karena proses intersepsi dan pengalihan lalu lintas pengguna ke content/cache engine dilakukan secara transparan oleh protokol WCCP (Web Cache Communication Protocol).

Konfigurasi content/cache engine dan router yang biasa diterapkan adalah dengan menggunakan satu atau lebih cache engine dan satu unit router. Fitur dari protokol WCCPv2 (Web Cache Communication Protocol version 2) mendukung penggunaan lebih dari satu unit router untuk setiap satu unit cache engine. Dalam dokumentasi yang disajikan oleh Cisco selaku pembuat router menyatakan bahwa dengan menggunakan WCCPv2, satu unit cache engine dapat berkomunikasi dengan jumlah maksimum sebanyak 32 unit router. Konsep penggunaan lebih dari 1 unit router dapat meningkatkan kehandalan jaringan dengan menyediakan mekanisme failover melalui desain yang redundan untuk memastikan tidak ada single link failure. ${ }^{[4]}$

\section{METODOLOGI PENELITIAN}

Metodologi penelitian yang digunakan pada perancangan sistem proxy server menggunakan protokol WCCPv2 dengan konfigursi multi router memiliki tahapan sebagai berikut, definisi sistem yang merupakan tahap mendefinisikan sistem yang akan dibuat, meliputi penjabaran sistem, identifikasi kebutuhan sistem, tujuan dan manfaat sistem, cara kerja dan topologi yang digunakan.

Proses spesifikasi kebutuhan akan menjabarkan tentang awal perancangan sistem dengan menentukan spesifikasi kebutuhan yang sesuai definisi sistem. Spesifikasi kebutuhan terdiri atas spesifikasi perangkat keras dan perangkat lunak. Kegiatan ini menentukan arsitektur sistem secara keseluruhan. Pada tahap ini telah ditentukan bahwa sistem ini akan dirancang dalam lingkungan virtual menggunakan aplikasi GNS3 sebagai emulator router. Sistem operasi yang digunakan 
adalah Ubuntu Server dan Desktop 14.04 yang dijalankan secara virtual dengan aplikasi VMware Fusion. Proxy server yang dirancang menggunakan aplikasi Squid 3.3.8. Protokol WCCP digunakan untuk mengalihkan lalu lintas web dari klien menuju proxy server. Protokol HSRP akan digunakan sebagai mekanisme failover untuk menyediakan ketersediaan tertinggi pada jaringan. Perangkat keras yang digunakan adalah 1 unit laptop MacBook Pro dengan prosesor Intel Core 2 Duo P8700 2,53 GHz, memory $4 \mathrm{~GB}$ dan hard disk $500 \mathrm{~GB}$.

Konfigurasi sistem, pada tahap ini spesifikasi kebutuhan yang telah ditentukan akan dirancang sesuai topologi/desain jaringan dan direalisasikan sebagai serangkaian sistem atau unit sistem yang memungkinkan untuk menjalankan tujuan sistem dan cara kerja sistem. Tahapan konfigurasi dilakukan melakukan konfigurasi yang sesuai pada semua komponen sistem, yaitu router, proxy server dan komputer host. Komputer host harus dikonfigurasi karena akan bertindak sebagai router yang menghubungkan semua perangkat dalam lingkungan virtual GNS3 ke jaringan di dunia nyata.

Pengujian sistem, yaitu proses pengujian dengan berbagai parameter tertentu untuk memastikan sistem dapat berjalan dengan baik dan dapat memenuhi fungsi dan tujuannya. Pada tahap ini, pengujian yang dilakukan mencakupi pengujian proxy server dan pengujian failover.

Analisis sistem, yaitu proses analisa data yang didapat dari pengujian kemudian dianalisis untuk mendapatkan hasil yang diinginkan. Analisis proxy server yang dilakukan untuk membuktikan apakah proxy server telah dapat bekerja dengan baik atau tidak. Hal tersebut dilakukan dengan melihat perbandingan data yang ada pada kondisi beberapa parameter ketika proxy server tidak aktif dan ketika proxy server telah aktif. Analisis performansi Squid juga dilakukan untuk menunjukkan bagaimana perilaku Squid selama pengujikan berlangsung. Analisis mekanisme failover dilakukan dengan melihat hasil pengujian yang akan menunjukkan waktu berapa lama standby router mengambil alih peran active router ketika active router mengalami kegagalan dan waktu berapa lama klien dapat terhubung kembali ke internet serta packet loss yang dialami oleh klien ketika terjadi kegagalan active router.

\section{PERANCANGAN SISTEM}

Definisi sistem akan menjabarkan awal sistem dibuat, tujuan, topologi jaringan dan cara kerja sistem yang akan digunakan untuk menentukan spesifikasi kebutuhan sistem ke tahapan selanjutnya, beberapa tahapan untuk bisa mendefinisikan sistem yang telah dibuat adalah sebagai berikut:

\section{A. Definisi Sistem}

Pada tahap awal ini, sistem dibuat dalam lingkungan virtual menggunakan aplikasi GNS3 dan aplikasi VMWare Fusion untuk mensimulasikan sistem operasi bagi proxy server dan klien. GNS3 merupakan aplikasi emulasi jaringan lintas platform yang dikembangkan oleh Christophe Fillot, Jeremy Grossman, Julien Duponchelle. Aplikasi ini memudahkan penggunanya melakukan percobaan dalam bentuk jaringan virtual di PC, (termasuk namun tidak terbatas pada) Cisco IOS, Juniper, Mikrotik, Arista dan Vyatta Network. ${ }^{[5]}$

Pilihan untuk melakukan penelitian pada lingkungan virtual karena tidak adanya perangkat router yang mendukung, dibutuhkan paling tidak 4 buah port Ethernet pada router untuk merealisasikan penelitian ini ke dalam perangkat fisik.
Sistem ini didesain terlebih dahulu menggunakan topologi jaringan. Topologi jaringan merupakan hal yang menjelaskan hubungan geometris antara unsur-unsur dasar penyusun jaringan, yaitu node, link, dan station. Topologi jaringan sistem ini dibuat dengan aplikasi GNS3 yang disusun sesuai kebutuhan sistem yang akan dibuat.

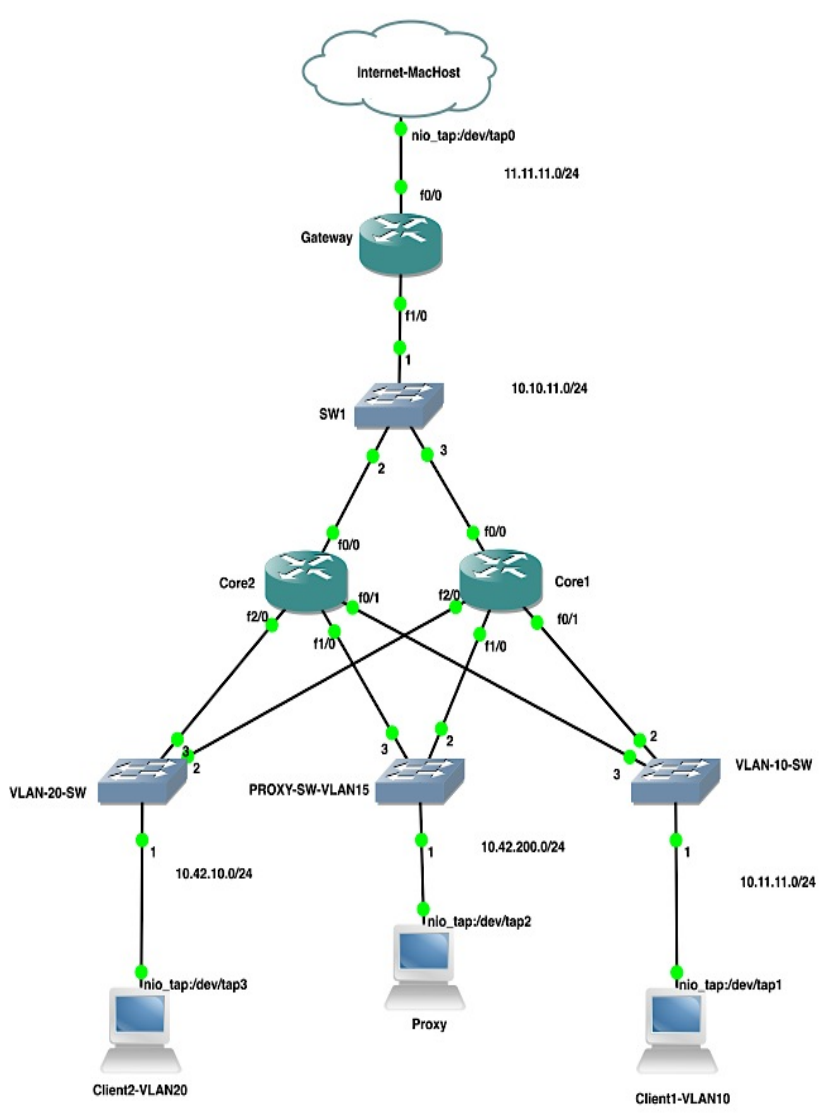

Gambar 1 Topologi Jaringan

Pada Gambar 1 di atas, terdapat dua buah sistem utama yang bekerja di dalamnya, yaitu sistem proxy server dengan menggunakan protokol WCCP yang digunakan untuk mengalihkan permintaan konten klien menuju proxy server, protokol WCCP menggunakan tunnel GRE (General Routing Encapsulation) diantara router dan proxy server yang menjalankan Squid. Permintaan yang dialihkan akan dibungkus (enkapsulasi) dengan GRE dan dikirim ke proxy server melalui tunnel GRE. Proses dekapsulasi paket GRE dan pengalihan ke Squid/LUSCA dilakukan oleh mesin host menggunakan IPTables. Kemudian Squid/LUSCA akan mengambil konten yang diminta dari server asli ataupun dari cache dan mengembalikan konten ke router. Router akan mengembalikan tanggapan dari proxy server tersebut ke pengguna. $^{[1]}$

Mekanisme failover dirancang dengan protokol HSRP yang digunakan untuk menyediakan ketersediaan tinggi pada jaringan. ${ }^{[3]}$ Cara kerja sistem proxy server dan mekanisme failover dari desain yang dibuat ditunjukkan oleh Gambar 2 dan Gambar 3. 


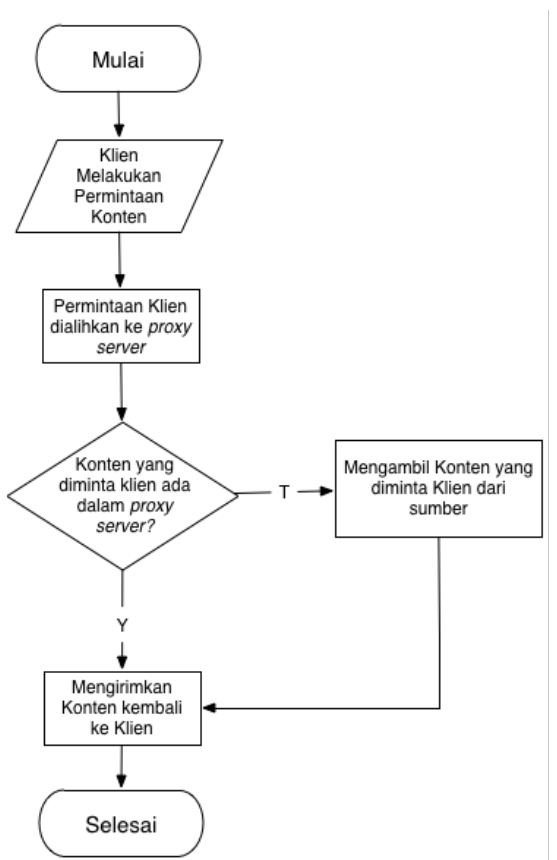

Gambar 2 Diagram alir cara kerja sistem proxy server

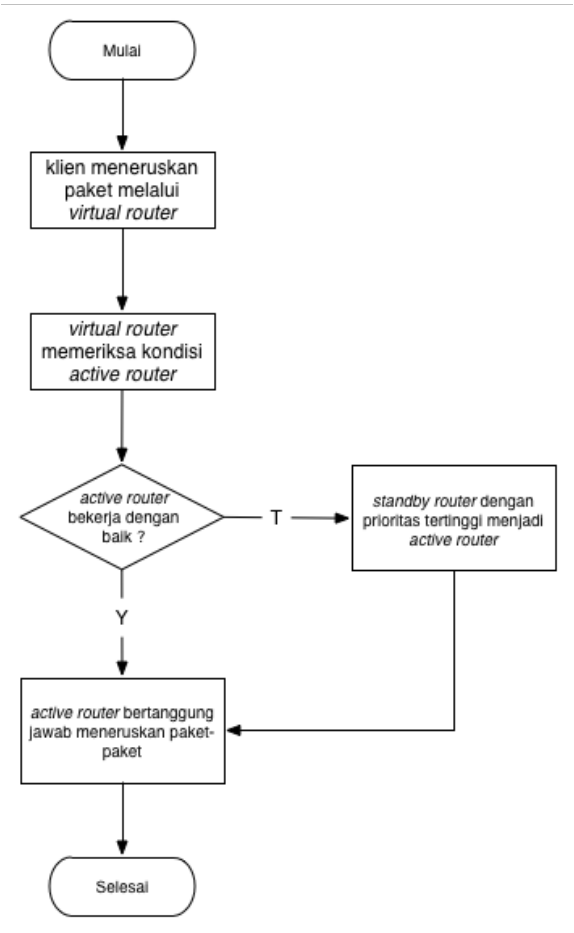

Gambar 3 Diagram alir cara kerja mekanisme failover

\section{B. Spesifikasi Kebutuhan}

Penelitian ini menggunakan perangkat keras berupa 1 buah perangkat laptop MacBook Pro dengan spesifikasi prosesor Intel Core 2 Duo P8700 2,53 GHz, hard disk 500GB dan memory sebesar 4GB. Perangkat lunak yang digunakan selama penelitian ini adalah sebagai berikut :

1. VMWare Fusion

Sistem operasi proxy server dan klien dijalankan secara virtual menggunakan aplikasi VMware Fusion 6.0.6 yang dipasang pada komputer host MacBook.

2. Sistem Operasi Ubuntu Server 14.04.3

Ubuntu merupakan salah satu distribusi Linux yang berbasiskan Debian dan didistribusikan sebagai perangkat lunak bebas.Ubuntu versi ini dirancang untuk kepentingan penggunaan server. Sistem operasi ini digunakan sebagai proxy server untuk menjalankan aplikasi Squid.

3. Sistem Operasi Ubuntu Desktop 14.04

Sistem operasi ini merupakan versi desktop dari Ubuntu Server yang sudah menyediakan tampilan GUI (Graphical User Interface) untuk kemudahan pengguna.

4. Squid/LUSCA

Squid adalah sebuah daemon yang digunakan sebagai server proxy dan web cache. Squid memiliki beberapa kegunaan, mulai dari mempercepat server web dengan melakukan caching permintaan yang berulang-ulang, caching Domain Name Server (DNS), caching situs web, dan caching pencarian komputer di dalam jaringan untuk sekelompok komputer yang berada pada jaringan yang sama, dan bisa juga untuk membantu keamanan dengan cara melakukan penyaringan (filtering) trafik. ${ }^{[6]}$ Sedangkan LUSCA adalah cabang pengembangan dari Squid versi 2. Proyek dari LUSCA digunakan untuk memperbaiki kekurangan dari Squid versi 2 namun tetap mempertahankan fungsi dan stabilitas dari Squid versi $2 .{ }^{[2]}$. Squid yang digunakan pada proxy server adalah versi 3.3.8.

\section{PENGUJIAN SISTEM}

Setelah konfigurasi sistem selesai diimplementasikan, pengujian dilakukan untuk memastikan sistem yang dibuat dapat berfungsi dengan baik. Pengujian yang dilakukan antara lain adalah sebagai berikut, yaitu pengujian proxy server dan pengujian mekanisme failover.

Pengujian proxy server menggunakan dua kondisi, yaitu pengujian ketika proxy server dalam keadaan mati dan pengujian dalam ketika proxy server dalam keadaan hidup. Skenario pengujian yang digunakan adalah klien dari VLAN 10 dan VLAN 20 akan melakukan simulasi permintaan HTTP sebanyak masing-masing 100 klien selama 30 menit ke 4 website yang berbeda. Selain itu, pengujian proxy server juga mencakup pengujian kemampuan dari proxy server untuk melakukan caching terhadap paket - paket update sistem operasi.

Pengujian mekanisme failover dilakukan dengan skenario dimana active router dari VLAN klien akan dimatikan dan parameter yang diuji ialah waktu pengambil alihan peran active router oleh standby router, waktu klien dapat kembali terhubung ke internet dan presentase packet loss.

\section{A. Pengujian proxy server}

Pengujian ini dilakukan dengan menggunakan aplikasi Siege yang dipasang pada komputer klien VLAN 10 dan VLAN 20 yang dilakukan pada dua kondisi, yaitu kondisi saat proxy server dalam keadaan tidak aktif dan pada saat proxy server dalam keadaan aktif. Selama pengujian, aplikasi Siege akan mensimulasikan permintaan HTPP setara dengan 100 orang ke 4 website yang berbeda secara acak. Setelah proses simulasi selesai, aplikasi Siege akan menunjukkan hasil dengan beberapa parameter. Pengujian proxy server juga mencakup pengujian kemampuan dari proxy server untuk melakukan caching terhadap paket - paket update sistem operasi. Parameter yang dihitung adalah waktu dan kecepatan unduh dari paket update sistem operasi ketika belum disimpan dalam proxy server dibandingkan dengan ketika paket update sudah tersimpan dalam proxy server. Presentase perubahan nilai setiap parameter dapat menunjukkan apakah proxy server sudah dapat bekerja dengan baik ataupun tidak. Tabel 1 di 
bawah ini menunjukkan presentase perubahan nilai rerata dari parameter yang ditunjukkan oleh aplikasi Siege setelah pengujian selesai.

Tabel 1 Tabel pengujian proxy server

\begin{tabular}{|c|c|c|c|}
\hline \multirow[t]{2}{*}{ Parameter } & $\begin{array}{l}\text { Sebelum } \\
\text { Proxy Server } \\
\text { Aktif }\end{array}$ & $\begin{array}{l}\text { Setelah } \\
\text { Proxy Server } \\
\text { Aktif }\end{array}$ & \multirow[t]{2}{*}{$\begin{array}{l}\text { Presentase } \\
\text { Perubahan }\end{array}$} \\
\hline & Nilai Rerata & Nilai Rerata & \\
\hline $\begin{array}{l}\text { Transaction } \\
\text { (hits)* }\end{array}$ & $4.529,5$ & 17.922 & $296 \%$ \\
\hline $\begin{array}{l}\text { Availability } \\
(\%)^{*}\end{array}$ & 82.67 & 99.96 & $21 \%$ \\
\hline $\begin{array}{ll}\begin{array}{l}\text { Elapsed } \\
\text { (detik) }\end{array} & \\
\end{array}$ & $1.799,54$ & $1.799,94$ & $0 \%$ \\
\hline $\begin{array}{l}\text { Data } \\
\text { Transferred } \\
(\mathrm{MB})^{*}\end{array}$ & 55,97 & 200,24 & $258 \%$ \\
\hline $\begin{array}{l}\text { Response Time } \\
\text { (detik)** }\end{array}$ & 13,32 & 10,91 & $-18 \%$ \\
\hline $\begin{array}{l}\text { Transaction } \\
\text { Rate } \\
\text { (trans/detik)* }\end{array}$ & 2,52 & 9,96 & $296 \%$ \\
\hline $\begin{array}{l}\text { Throughput } \\
\text { (MB/detik)* }^{*}\end{array}$ & 0,03 & 0,11 & $267 \%$ \\
\hline Concurrency* & 37,9 & 90,92 & $140 \%$ \\
\hline $\begin{array}{l}\text { Successful } \\
\text { Transaction* }\end{array}$ & $4.686,5$ & $17.973,5$ & $284 \%$ \\
\hline $\begin{array}{l}\text { Failed } \\
\text { Transaction** }\end{array}$ & 765,5 & 4,5 & $-99 \%$ \\
\hline $\begin{array}{l}\text { Longest } \\
\text { Transaction } \\
\text { (detik)** }^{* *}\end{array}$ & 266,3 & 226,25 & $-15 \%$ \\
\hline $\begin{array}{l}\text { Shortest } \\
\text { Transaction } \\
(\text { detik)** }\end{array}$ & 0.69 & 1.6 & $134 \%$ \\
\hline
\end{tabular}

$*$ = semakin besar semakin baik

** = semakin kecil semakin baik

Pada Tabel 1 di atas, dapat diambil beberapa parameter yang menunjukkan bahwa proxy server telah dapat bekerja dengan baik, antara lain parameter transaction, response time dan failed transaction. Parameter transction mengalami kenaikan hingga 296\% dari 4.529,2 hit menjadi 17.922 hit saat proxy server aktif. Parameter response time dan failed transaction secara berurutan mengalami penurunan $18 \%$ dan 99\% pada saat proxy server aktif.

Berikut ini merupakan pengujian caching terhadap paket - paket yang digunakan dalam melakukan pembaruan sistem operasi. Pengujian berlangsung dengan cara memberikan perintah apt-get upgrade pada aplikasi terminal. Apt-get upgrade berfungsi untuk melakukan pembaruan paket - paket pada aplikasi yang telah terpasang pada sistem operasi. Bagaimana Squid akan menangani umur paket dapat dimanipulasi menggunakan perintah refresh pattern pada konfigurasi Squid. Pada pengujian kali ini umur paket pembaruan dianggap dalam kondisi FRESH selama 30 menit saja, jika lebih dari itu paket tersebut akan dianggap STALE (kedaluwarsa). Ukuran dari paket pembaruan yang akan diunduh selama pengujian adalah 64,4 MB.

Pengujian dilakukan sebanyak 4 kali, yaitu Pengujian 1 hingga Pengujian 4. Pengujian 1 pada klien VLAN 10 saat proxy server dalam kondisi kosong, artinya tidak ada paket pembaruan yang tersimpan dalam cache. Pengujian 2 dilakukan pada klien VLAN 20, dengan kondisi proxy server telah menyimpan paket pembaruan yang telah diunduh pada Pengujian 1. Pengujian 3 dilakukan pada klien VLAN 20, 30 menit setelah Pengujian 2 selesai dengan asumsi paket pembaruan yang telah disimpan oleh proxy server sudah dalam keadaan STALE (kedaluwarsa). Pengujian 4 dilakukan setelah pada klien VLAN 10 dengan keadaan paket pembaruan dalam proxy server telah berada dalam kondisi FRESH kembali. Tabel 2 dan 3 dibawah ini menunjukkan hasil Pengujian 1 hingga Pengujian 4.

Tabel 2 Tabel pengujian pembaruan sistem operasi klien

\begin{tabular}{|c|c|c|c|}
\hline \multirow[b]{2}{*}{ Parameter } & \multirow{2}{*}{$\begin{array}{l}\begin{array}{c}\text { Pengujian } 1 \\
(\mathrm{P} 1)\end{array} \\
\text { VLAN } 10\end{array}$} & \multicolumn{2}{|c|}{ Pengujian 2 (P2) } \\
\hline & & $\begin{array}{l}\text { VLAN } \\
20\end{array}$ & $\begin{array}{c}\text { Presentase } \\
\text { Perubahan } \\
(\mathrm{P} 2: \mathrm{P} 1)\end{array}$ \\
\hline $\begin{array}{l}\text { Waktu Unduh } \\
(\text { detik)** }\end{array}$ & 293 & 42 & $-86 \%$ \\
\hline $\begin{array}{l}\text { Kecepatan } \\
(\mathrm{kB} / \text { detik) }\end{array}$ & 219 & 1528 & $598 \%$ \\
\hline
\end{tabular}

Tabel 3 Tabel pengujian pembaruan sistem operasi klien - 2

\begin{tabular}{|c|c|c|c|c|}
\hline \multirow{2}{*}{ Parameter } & \multicolumn{2}{|c|}{ Pengujian 3 (P3) } & \multicolumn{2}{c|}{ Pengujian 4 (P4) } \\
\cline { 2 - 5 } & $\begin{array}{c}\text { VLA } \\
\text { N 20 }\end{array}$ & $\begin{array}{c}\text { Presentase } \\
\text { Perubahan } \\
\text { (P3 : P2) }\end{array}$ & $\begin{array}{c}\text { VLAN } \\
10\end{array}$ & $\begin{array}{c}\text { Presentase } \\
\text { Perubahan } \\
\text { (P4 : P3) }\end{array}$ \\
\hline $\begin{array}{c}\text { Waktu } \\
\text { Unduh } \\
\text { (detik)** }\end{array}$ & 55 & $31 \%$ & 40 & $-27 \%$ \\
\hline $\begin{array}{c}\text { Kecepatan } \\
\text { (kB/detik)* }\end{array}$ & 1154 & $-24 \%$ & 1571 & $36 \%$ \\
\hline
\end{tabular}

$*=$ semakin besar semakin baik

$* *=$ semakin kecil semakin baik

Tabel 2 dan 3 menunjukkan bagaimana perubahan waktu dan kecepatan unduh paket pembaruan selama pengujian. Pengujian 1 menunjukkan kecepatan unduh sebesar $219 \mathrm{kB} /$ detik dengan waktu selama 293 detik. Pengujian 2 dilakukan setelah Pengujian 1 dilakukan dengan kondisi paket pembaruan telah tersimpan dalam proxy server. Pengujian 2 menunjukkan kecepatan unduh sebesar $1.528 \mathrm{kB} /$ detik dengan waktu selama 42 detik. Presentase perubahan waktu dan kecepatan dibandingkan dengan Pengujian 1 adalah sebesar $86 \%$ dan 598\%. Perubahan yang signifikan tersebut disebabkan oleh proxy server yang telah menyimpan paket pembaruan yang sebelumnya telah diunduh pada Pengujian 1, sehingga permintaan klien dapat dipenuhi secara lokal tanpa harus langsung meminta ke server tujuan.

Pengujian 3 dilakukan 30 menit setelah Pengujian 2 dengan keadaan paket pembaruan yang tadi telah diunduh pada Pengujian 1 sudah dalam keadaan STALE (kedaluwarsa). Pengujian 3 menunjukkan kecepatan unduh sebesar 1.154 kB/detik dengan waktu selama 55 detik. Presentase perubahan waktu unduh terhadap Pengujian 2 mengalami kenaikan sebesar $31 \%$ dan kecepatan unduh mengalami penurunan sebesar 24\%. Kenaikan waktu unduh dan penurunan kecepatan disebabkan ketika klien melakukan permintaan terhadap paket 
pembaruan, paket tersebut sudah dalam keadaan STALE, sehingga Squid terlebih dahulu akan menghubungi server asal paket untuk melakukan validasi terhadap paket tersebut. Jika paket tersebut masih dinyatakan valid oleh server asal, Squid akan mengirimkan paket yang telah tersimpan dalam cache ke klien. Jika paket dinyatakan tidak valid, Squid akan mengunduh paket terbaru yang valid dan kemudian baru dikirimkan menuju klien. Pengujian 4 dilakukan setelah paket pembaruan yang tadi telah STALE kembali diperbarui sehingga dalam kondisi FRESH. Pengujian 4 menunjukkan kecepatan unduh sebesar $1.571 \mathrm{kB} /$ detik dengan waktu selama 40 detik. Presentase perubahan waktu dan kecepatan unduh Pengujian 4 terhadap Pengujian 3 adalah $-27 \%$ dan $36 \%$. Penurunan waktu unduh dan kenaikan kecepatan unduh paket disebabkan oleh permintaan klien yang sudah dapat dipenuhi secara lokal oleh proxy server.

\section{B. Performansi Squid selama pengujian proxy server}

Selama pengujian berlangsung, kinerja dari Squid dapat dipantaun melalui aplikasi monitorix. Aplikasi ini akan menerjemahkan aktifitas dari Squid melalui access.log Squid. Semua aktifitas akses Squid tercatat pada log tersebut. Gambar 5 di bawah ini menunjukkan grafik kinerja Squid selama pengujian.

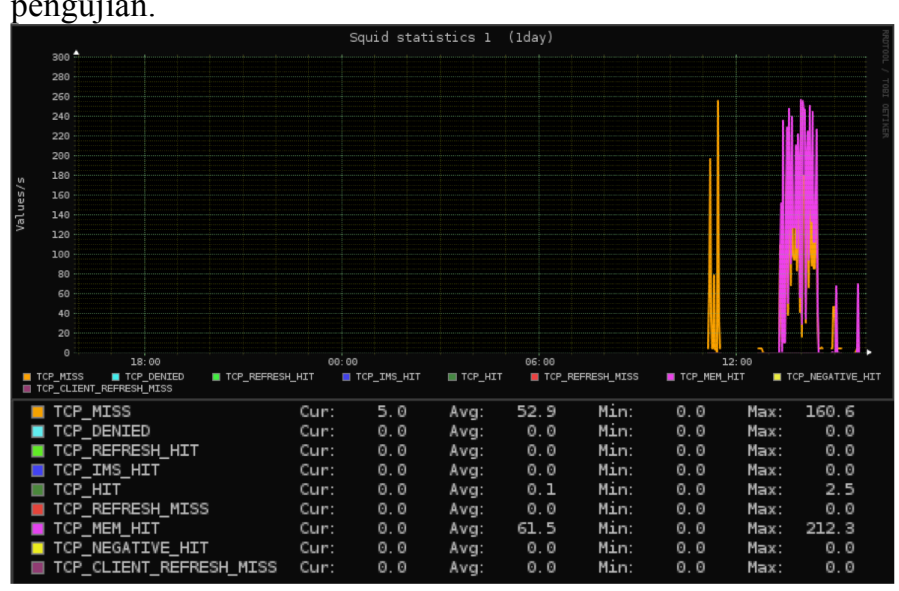

Gambar 4 Grafik kinerja Squid selama pengujian

Gambar 4 di atas menunjukkan informasi mengenai respon Squid selama pengujian berlangsung. TCP_HIT merupakan respon ketika konten yang diminta oleh klien sudah berada dalam cache dan dalam kondisi fresh. TCP IMS HIT merupakan kondisi ketika klien mengeluarkan permintaan IMS (If-Modified-Since) terhadap objek/konten yang telah ada dalam cache dengan kondisi fresh. TCP_MEM_HIT merupakan kondisi ketika konten yang diminta oleh $\bar{k}$ lien masih tersimpan dalam memory, dalam hal ini merupakan RAM dari proxy server. TCP_MISS merupakan kondisi dimana konten yang diminta oleh klien tidak ada dalam cache dan Squid akan langsung mengambil konten yang diminta tersebut dari sumbernya. Informasi mengenai jumlah dari respon Squid di atas dapat dilihat pada Tabel 4 dibawah ini.

Tabel 4 Tabel Performansi Squid

\begin{tabular}{|c|c|c|c|}
\hline $\begin{array}{c}\text { N } \\
\text { o }\end{array}$ & $\begin{array}{c}\text { Respon } \\
\text { Squid }\end{array}$ & $\begin{array}{c}\text { Jumlah rata-rata } \\
\text { (values } / s \text { ) }\end{array}$ & $\begin{array}{c}\text { Jumlah Maksimum } \\
\text { (values } / s \text { ) }\end{array}$ \\
\hline 1 & TCP_MISS & 52,9 & 160,6 \\
\hline \multicolumn{2}{|c|}{ TOTAL MISS } & $\mathbf{5 2 , 9}$ & $\mathbf{1 6 0 , 6}$ \\
\hline 2 & TCP_HIT & 0,1 & 2,5 \\
\hline
\end{tabular}

\begin{tabular}{|c|c|c|c|}
\hline $\begin{array}{c}\mathrm{N} \\
\text { o }\end{array}$ & $\begin{array}{c}\text { Respon } \\
\text { Squid }\end{array}$ & $\begin{array}{c}\text { Jumlah rata-rata } \\
\text { (values } / \text { s })\end{array}$ & $\begin{array}{c}\text { Jumlah Maksimum } \\
\text { (values } / \mathrm{s})\end{array}$ \\
\hline 3 & $\begin{array}{c}\text { TCP_MEM } \\
\text { HIT }\end{array}$ & 61,5 & 212,3 \\
\hline \multicolumn{2}{|c|}{ TOTAL HIT } & $\mathbf{6 1 , 6}$ & $\mathbf{2 1 4 , 8}$ \\
\hline
\end{tabular}

Tabel 4 di atas menunjukkan informasi performa Squid ketika pengujian. Berdasarkan tabel tersebut diketahui bahwa respon rerata TCP_MISS selama pengujian adalah 52,9 values/detik dengan jumlah maksimum 160,6 values/detik. Respon rerata TCP_HIT selama pengujian adalah 0,1 values/detik dengan jumlah maksimum 2,5 values/detik. Rerata respon TCP_MEM_HIT selama pengujian adalah 61,5 values/detik dengan jumlah maksimum 212,3 values/detik. Jumlah total permintaan dengan respon MISS adalah 52,9 vales/detik dan total respon permintaan HIT adalah 61,6 values/detik.

Berdasarkan keterangan di atas diketahui bahwa selama pengujian berlangsung, Squid telah dapat melayani permintaan klien dengan cukup baik. Hal ini ditandai dengan jumlah permintaan dengan respon HIT berada di atas permintaan dengan respon MISS yang bernilai 61,6 values/detik berbanding 52,9 values/detik.

\section{Pengujian Mekanisme failover}

Pengujian failover dilakukan dengan menonaktifkan interface dari active router VLAN. Parameter yang digunakan adalah selang waktu pengambil alihan peran active router oleh standby router dan presentase packet loss pada klien. Pengujian ini menggunakan perintah ping yang ditujukan ke situs www.google.com yang dilakukan sebanyak 3 kali untuk masing - masing VLAN klien. Nilai yang didapat dari ketiga pengujian akan dirata-rata untuk mendapat hasil pengujian.

\begin{tabular}{|c|c|c|c|c|}
\hline \multirow{3}{*}{ Parameter/Network } & \multicolumn{4}{|c|}{ VLAN 10} \\
\hline & \multicolumn{4}{|c|}{ Pengujian } \\
\hline & 1 & 2 & 3 & Rerata \\
\hline $\begin{array}{l}\text { Waktu Non Aktif } \\
\text { Active } \\
\text { (hh:mm:ss) }\end{array}$ & $\begin{array}{l}02: 45: 2 \\
5.381\end{array}$ & $\begin{array}{l}02: 49: 2 \\
5.198\end{array}$ & $\begin{array}{l}02: 57: 3 \\
2.991\end{array}$ & - \\
\hline $\begin{array}{lr}\text { Waktu } & \text { Standby } \\
\text { Router } & \text { menjadi } \\
\text { Active } & \text { Router } \\
\text { (hh:mm:ss) } & \\
\end{array}$ & $\begin{array}{l}02: 45: 2 \\
5.422\end{array}$ & $\begin{array}{l}02: 49: 2 \\
5.258\end{array}$ & $\begin{array}{l}02: 57: 3 \\
3.060\end{array}$ & - \\
\hline $\begin{array}{l}\text { Selisih } \\
\text { Takeover (detik) }\end{array}$ & 0,041 & 0,06 & 0,069 & 0,057 \\
\hline
\end{tabular}

Tabel 6 Tabel pengujian failover klien VLAN 10

\begin{tabular}{|c|c|c|c|c|}
\hline \multicolumn{5}{|c|}{ VLAN 10} \\
\hline $\begin{array}{l}\text { Pen } \\
\text { guji } \\
\text { an }\end{array}$ & $\begin{array}{l}\text { Sekuens } \\
\text { Koneksi } \\
\text { Terputus } \\
\end{array}$ & $\begin{array}{l}\text { Sekuens Koneksi } \\
\text { Tersambung } \\
\text { Kembali }\end{array}$ & $\begin{array}{l}\text { Selisih } \\
\text { Waktu } \\
\text { (detik) } \\
\end{array}$ & $\begin{array}{l}\text { Packet } \\
\text { Loss } \\
(\%) \\
\end{array}$ \\
\hline 1 & 13 & 22 & 9 & 34 \\
\hline 2 & 9 & 15 & 6 & 30 \\
\hline 3 & 11 & 17 & 6 & 30 \\
\hline \multicolumn{3}{|r|}{ Total } & 21 & - \\
\hline \multicolumn{3}{|r|}{ Rerata } & 7 & 31.3 \\
\hline
\end{tabular}


Tabel 5 dan Tabel 6 di atas merupakan hasil pengujian failover pada klien VLAN 10. Berdasarkan Tabel 4 di atas, menunjukkan selisih waktu pengambil alihan active router oleh standby router dari VLAN 10 dalam tiga pengujian secara berurutan adalah 0,041 detik, 0,06 detik dan 0,069 detik dengan rerata 0,057 detik. Berdasarkan informasi pada Tabel 5 di atas diketahui bahwa pada pengujian 1 hingga pengujian 3 selisih waktu klien untuk dapat tersambung kembali ke internet secara berurutan adalah 9 detik, 6 detik dan 6 detik dengan rerata 7,1 detik. Presentase packet loss selama pengujian pertama hingga ketiga secara berurutan adalah 34\%, 30\% dan $30 \%$ dengan rerata $31,3 \%$.

Tabel 7 Tabel pengujian failover router VLAN 20

\begin{tabular}{|c|c|c|c|c|}
\hline \multirow{3}{*}{ Parameter/Network } & \multicolumn{4}{|c|}{ VLAN 20} \\
\hline & \multicolumn{4}{|c|}{ Pengujian } \\
\hline & 1 & 2 & 3 & Rerata \\
\hline $\begin{array}{l}\text { Waktu Non Aktif } \\
\text { Active } \\
\text { (hh:mm:ss) }\end{array}$ & $\begin{array}{l}01: 26: 5 \\
6.051\end{array}$ & $\begin{array}{l}01: 29: 0 \\
7.559\end{array}$ & $\begin{array}{l}01: 35: 4 \\
4.182\end{array}$ & - \\
\hline $\begin{array}{lr}\text { Waktu } & \text { Standby } \\
\text { Router } & \text { menjadi } \\
\text { Active } & \text { Router } \\
\text { (hh:mm:ss) } & \\
\end{array}$ & $\begin{array}{l}01: 26: 5 \\
6.077 \\
\end{array}$ & $\begin{array}{l}01: 29: 0 \\
7.661\end{array}$ & $\begin{array}{l}01: 35: 4 \\
4.236\end{array}$ & - \\
\hline $\begin{array}{l}\text { Selisih Waktu } \\
\text { Takeover (detik) }\end{array}$ & 0,026 & 0,102 & 0,054 & 0,061 \\
\hline
\end{tabular}

Tabel 8 Tabel pengujian failover klien VLAN 20

\begin{tabular}{|c|c|c|c|c|}
\hline \multicolumn{5}{|c|}{ VLAN 20} \\
\hline $\begin{array}{l}\text { Pen } \\
\text { guji } \\
\text { an }\end{array}$ & $\begin{array}{l}\text { Sekuens } \\
\text { Koneksi } \\
\text { Terputus }\end{array}$ & $\begin{array}{l}\text { Sekuens Koneksi } \\
\text { Tersambung } \\
\text { Kembali }\end{array}$ & $\begin{array}{l}\text { Selisih } \\
\text { Waktu } \\
\text { (detik) }\end{array}$ & $\begin{array}{l}\text { Packet } \\
\text { Loss } \\
(\%) \\
\end{array}$ \\
\hline 1 & 4 & 10 & 6 & 27 \\
\hline 2 & 8 & 14 & 6 & 25 \\
\hline 3 & 5 & 11 & 6 & 27 \\
\hline \multicolumn{3}{|r|}{ Total } & 18 & - \\
\hline \multicolumn{3}{|c|}{ Rerata } & 6 & 26.3 \\
\hline
\end{tabular}

Tabel 7 dan Tabel 8 di atas merupakan hasil pengujian failover pada klien VLAN 20. Berdasarkan Tabel 6 di atas, menunjukkan selisih waktu pengambil alihan active router oleh standby router dari VLAN 10 dalam tiga pengujian secara berurutan adalah 0,026 detik, 0,102 detik dan 0,054 detik dengan rerata 0,061 detik. Berdasarkan informasi pada Tabel 7 di atas diketahui bahwa pada pengujian 1 hingga pengujian 3 selisih waktu klien untuk dapat tersambung kembali ke internet secara berurutan adalah 6 detik dengan rerata 6 detik. Presentase packet loss selama pengujian pertama hingga ketiga secara berurutan adalah $27 \%, 25 \%$ dan $27 \%$ dengan rerata $26,3 \%$.

Ketika active router dari masing - masing VLAN sudah dapat kembali bekerja secara normal, kondisi (state) dari active router tersebut akan berubah menjadi dari Init menjadi Standby yang kemudian akan berubah kembali menjadi Active dengan waktu delay sebanyak minimum 30 detik untuk memberikan waktu pada router dalam mengumpulkan tabel routing-nya.

\section{PENUTUP}

\section{A. Kesimpulan}

Selama pengembangan sistem ini terdapat beberapa hal yang bisa disimpulkan. Kesimpulan yang didapatkan antara lain :

1. Desain dan implementasi proxy server menggunakan protokol WCCP (Web Cache Communication Protocol) dengan konfigurasi multi router telah berhasil dibuat.

2. Proxy server yang dibuat menggunakan aplikasi Squid. Pengujian proxy server yang dilakukan dalam dua kondisi, kondisi pertama pengujian yang dilakukan ketika Squid berada dalam keadaan mati dan pengujian kedua dilakukan ketika Squid berada dalam keadaan hidup. Perbandingan nilai rerata beberapa parameter selama pengujian menunjukkan bahwa Squid sudah dapat bekerja dengan baik. Parameter transaction dan successful transaction, yang secara berurutan mengalami kenaikan sebesar 296\% dan $284 \%$ serta response time dan failed transaction yang mengalami penurunan sebesar $18 \%$ dan $99 \%$.

3. Berdasarkan pengamatan terhadap performansi Squid selama pengujian, didapatkan rerata respon TCP_MISS selama pengujian adalah 52,9 values/detik dengan jumlah maksimum 160,6 values/detik. Rerata respon TCP HIT selama pengujian adalah 0,1 values/detik dengan jumlah maksimum 2,5 values/detik. Rerata respon TCP_MEM_HIT selama pengujian adalah 61,5 values/detik dengan jumlah maksimum 212,3 values/detik. Berdasarkan keterangan di atas diketahui bahwa selama pengujian berlangsung, Squid telah dapat melayani permintaan klien dengan cukup baik. Hal ini ditandai dengan jumlah permintaan dengan respon HIT berada di atas permintaan dengan respon MISS yang bernilai 61,6 values/detik berbanding 52,9 values/detik.

4. Pengujian proxy server juga mencakup pengujian kemampuan Squid untuk melakukan caching terhadap paket - paket pembaruan sistem operasi. Pengujian 1 menunjukkan kecepatan unduh sebesar 219 kB/detik dengan waktu selama 293 detik. Pengujian 2 menunjukkan kecepatan unduh sebesar $1.528 \mathrm{kB} /$ detik dengan waktu selama 42 detik. Presentase perubahan waktu dan kecepatan dibandingkan dengan Pengujian 1 adalah sebesar $-86 \%$ dan $598 \%$. Perubahan yang signifikan tersebut disebabkan oleh proxy server yang telah menyimpan paket pembaruan yang sebelumnya telah diunduh pada Pengujian 1, sehingga permintaan klien dapat dipenuhi secara lokal tanpa harus langsung meminta ke server tujuan. Pengujian 3 menunjukkan kecepatan unduh sebesar $1.154 \mathrm{kB} /$ detik dengan waktu selama 55 detik. Presentase perubahan waktu unduh terhadap Pengujian 2 mengalami kenaikan sebesar 31\% dan kecepatan unduh mengalami penurunan sebesar $24 \%$. Kenaikan waktu unduh dan penurunan kecepatan disebabkan ketika klien melakukan permintaan terhadap paket pembaruan, paket tersebut sudah dalam keadaan STALE, sehingga Squid terlebih dahulu akan menghubungi server asal paket untuk melakukan validasi terhadap paket tersebut. Pengujian 4 menunjukkan kecepatan unduh sebesar $1.571 \mathrm{kB} /$ detik dengan waktu selama 40 detik. Presentase perubahan waktu dan kecepatan unduh Pengujian 4 terhadap Pengujian 3 adalah $-27 \%$ dan $36 \%$. Penurunan waktu unduh dan kenaikan 
kecepatan unduh paket disebabkan oleh permintaan klien yang sudah dapat dipenuhi secara lokal oleh proxy server.

5. Pengujian failover pada active router VLAN klien menunjukkan bahwa masing - masing standby router dari setiap klien dapat mengambil alih peran active router dalam rerata waktu kurang dari 1 detik. Standby router VLAN 10 membutuhkan rerata waktu sebesar 0,057 detik dan VLAN 20 sebesar 0,061 detik.

6. Pada sisi klien, ketika pengujian failover berlangsung dibutuhkan waktu dengan rerata sebesar 7 detik untuk klien VLAN 10 dan 6 detik untuk VLAN 20 agar dapat kembali terhubung ke internet. Rerata jumlah packet loss yang dialami oleh setiap klien secara berurutan untuk VLAN 10 dan VLAN 20 adalah 31,3\% dan 26,3\%.

\section{B. Saran}

1. Implementasi yang dilakukan pada penelitian ini baru sebatas di lingkungan virtual. Hasil yang ditunjukkan oleh pengujian sangat bergantung pada kemampuan komputer host yang dipakai. Dibutuhkan implementasi lebih lanjut pada perangkat fisik aslinya untuk mendapatkan hasil yang lebih baik. Implementasi pada perangkat fisik membutuhkan paling tidak perangkat router yang dilengkapi minimal 4 buah port Ethernet
2. Penelitian lanjutan dengan menambahkan jumlah proxy server yang digunakan untuk meringankan beban kerja dari proxy server itu sendiri.

3. Penelitian lanjutan dengan menambahkan fitur untuk menambah dukungan pada protokol HTTPS.

\section{DAFTAR PUSTAKA}

[1] Andriyono, "Impact Proxy Server Terhadap Jaringan Internet," no. 3, pp. 1-7, 2007.

[2] Chadd, Adrian, "Lusca Web Proxy Cache," 2010. [Online]. Available:

https://sites.google.com/site/luscaproxy/Home.

[Accessed: 29-Nov-2015].

[3] Cisco Systems Inc., Cisco IOS IP Configuration Guide. San Jose, CA: Cisco Systems, Inc, 2006.

[4] Lammle, Todd, CCNA - Cisco Certified Network Associate, Second. Alameda, CA: SYBEX, Inc, 2012.

[5] Neumann, Jason C., The Book of GNS3, First. San Fransisco, CA: No Starch Press Inc., 2015.

[6] Saini, Kulbir, Squid Proxy Server 3.1 Beginner's Guide. Birmingham, UK: Packt Publishing, 2011. 